\title{
Germination of Wheat Seeds Exposed to Cold Atmospheric Plasma in Dry and Wet Plasma-Activated Water and Mist
}

\author{
M. El Shaer, ${ }^{*}$ H. El Welily, A. Zaki, H. Arafa, A. EISebaei, M. EIDaly, \& \\ M. Mobasher
}

Plasma \& Energy Applications Research Laboratory, Zagazig, Department of Engineering Physics and Mathematics, Faculty of Engineering, Zagazig University, Zagazig, Egypt

*Address all correspondence to: M. El Shaer, Faculty of Engineering, Zagazig University, Zagazig 44599, Egypt; Tel.: +20-100-695-0077; Fax: +20552304987, E-mail: melshaer2901@gmail.com

\begin{abstract}
We apply different cold atmospheric plasma (CAP) configurations to treat wheat seeds using (1) a direct atmospheric plasma jet (APJ) in the dry form, (2) indirect plasma-activated water (PAW) in the soaked form, and (3) plasma-activated mist (PAMI) in the wet form. Wheat seedling germination parameters including germination potential, germination index, vigor index, and shoot and root lengths are measured for different plasma treatment-time intervals. Seed germination and seedling growth of wheat specimens are enhanced compared to those of untreated controls. Indirect wet PAW and PAMI show higher wheat germination compared to that of dry direct APJ. During plasma treatment, a rise in hydrophilization of seed surface coat is accompanied by increased water uptake of treated seeds. Ozone generated by plasma shows an increase in all discharge conditions, but this increase is reduced for higher relative humidity values in the PAMI mode. During treatment, $\mathrm{OH}$ radicals that are generated by APJ increase largely near seed surfaces. Regarding seed germination, PAW shows a larger impact than PAMI. However, PAMI can be considered to be the more practical technique for treating large numbers of seeds at an industrial scale.
\end{abstract}

KEY WORDS: cold atmospheric plasma, wheat seedlings, seed germination, plasma-activated water, plasma-activated mist

\section{INTRODUCTION}

Increasing productivity for major crops creates huge challenges in both developed and developing countries. Despite the limited food resources that are available in some parts of the world, applying innovative and high-tech processes to agriculture can help to satisfy food sufficiency and demands of an increasing world population. ${ }^{1}$ However, it is important that applications of modern practices in this area produce minimum adverse environmental effects. This can be attained by respecting green technology principles and assuring that agriculture is free from harmful chemicals. ${ }^{2}$ Plasma technology may be one of most interesting candidates to satisfy such requirements. ${ }^{3}$ Nonthermal plasma applications, particularly those using cold atmospheric plasma (CAP), have shown beneficial results for increasing agriculture productivity in a safe, cost-effective, and environmentally friendly manner. ${ }^{4}$ In agriculture and food processing, CAP has been applied to different biosubstances directly or through plasma-activated media such as water or 
water mist to increase productivity or fight diseases and pathogens.$^{5,6}$ Wheat is one of the most strategic crops for increasing food security, ${ }^{7}$ and CAP has been revealed as a valuable method for enhancing wheat seed germination. ${ }^{8,9}$ During wheat seed plasma treatment, CAP by its uniform behavior can replace traditional presowing treatment, either physically or chemically. ${ }^{10-12}$ In this work, we applied dry and wet plasma discharges to surfaces of wheat seeds using the following three exposure schemes: (1) directly by dry application of atmospheric plasma jet (APJ) to seeds, (2) indirectly by wet application using plasma-activated water (PAW) to cover seeds, and (3) indirectly by wet application using plasma-activated mist (PAMI) that we sprayed onto seeds. Comparisons are made to identify effects of these three plasma activation schemes on wheat germination parameters.

\section{MATERIALS AND METHODS}

\section{A. Experimental Setup}

Plasma configurations were operated using coaxial dielectric barrier discharge (DBD), in which plasma discharges occur between two metallic electrodes separated by a dielectric insulation material to prevent arcing. ${ }^{13}$ The first scheme, shown in Fig. 1(a), consisted of an argon APJ between central and annular coaxial electrodes that were situated outside of the quartz discharge tube. APJ was applied directly to dry seeds in

A

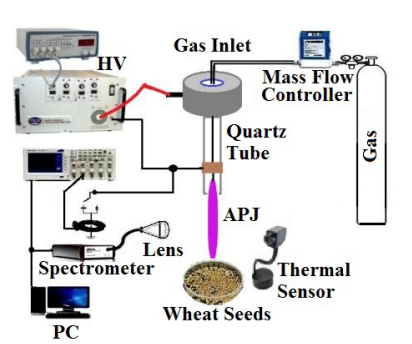

B

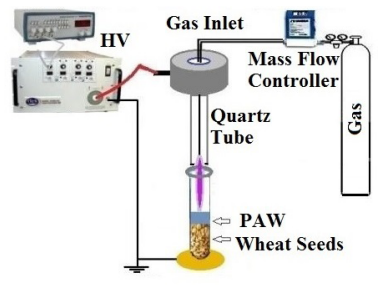

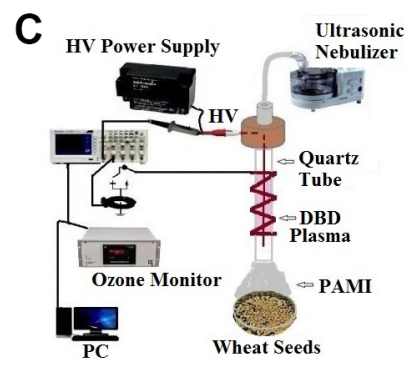

FIG. 1: Plasma configurations: (a) direct dry APJ; (b) indirect wet PAW; (c) indirect wet PAMI. DBD, dielectric barrier discharge; HV, high voltage; PAMI, plasma-activated mist; PAW, plasmaactivated water; PC, personal computer 
a Petri dish. Details of the plasma jet operation are described by El Shaer et al. ${ }^{14}$ Argon gas was injected to initiate the plasma jet of a few centimeters long by applying $5.7 \mathrm{kHz}$ of alternating-current high voltage of $5 \mathrm{kV}$ peak to peak and $15 \mathrm{~mA}$ of current. Figure 1(b) presents an indirect method that uses plasma-activated water (PAW) to treat seeds. Plasma was generated by an arrangement similar to that shown in Fig. 1(a), with the exception that a ground electrode was situated at the bottom of the test tube that contained wheat seeds immersed in $2 \mathrm{~mL}$ of distilled water. In the third discharge scheme shown in Fig. 1(c), plasma was generated by a coaxial DBD in ambient air with a spray of water mist. The power supply used in this mode of operation was a common ignition transformer (Satronic ZT 931, Honeywell Inc., Charlotte, North Carolina, USA) that delivered voltage of $14 \mathrm{kV}$ and a root-mean-square current of $40 \mathrm{~mA}$ at a frequency of $20 \mathrm{kHz}$. Discharge gas was ambient air mixed with water mist, delivered by a commercial ultrasonic nebulizer (model W001, Jiangsu Folee Medical Equipment Co. Ltd., Zhenjiang City, China) that produced water droplets measuring $30 \mu \mathrm{m}$ in diameter.

\section{B. Calculations of Seed Germination}

From the Agriculture Research Centre (ARC) in Egypt, we obtained winter durum wheat lines (Triticum durum Desf.) of a local variety called Beni Suef 6. From wheat seeds harvested during May and June 2018, we selected ripe intact seeds of uniform size without visible defects and stored them in a dry location at maximum temperature of $23^{\circ} \mathrm{C}$ and relative humidity $(\mathrm{RH})<60 \%$. Seeds were exposed to plasma discharges in the three plasma configurations, either dry or wet, for different time intervals. A total of 99 wheat seeds were treated by plasma for $1-5 \mathrm{~min}$ and then soaked in water for $5 \mathrm{~h}$ before seedlings germinated. For statistical purposes, the 99 plasma-treated seeds, during each time interval, were distributed into three groups of 33 seeds that were arranged over two layers of filter paper in three Petri dishes. Figure 2(a) shows a Petri dish containing wheat seeds.

To study seedling germination for a certain plasma exposure time interval, we added $2 \mathrm{~mL}$ of distilled water to each of the three Petri dishes containing wheat seeds and kept them for $2 \mathrm{~d}$ in a dark environment at $\sim 20^{\circ} \mathrm{C}$. We followed seedling development until they reached $4 \mathrm{~d}$ of germination, at which time we counted the number of germinated seeds in each Petri dish to calculate germination parameters. Seedlings continued to grow, reaching $10 \mathrm{~d}$ of germination, when we calculated shoot and root lengths. A slight amount of water was added to maintain moisture during germination. We randomly chose five seedling samples from each dish, as shown in Fig. 2(b), to measure total shoot and root lengths. We measured lengths with a Vernier caliper, as shown in Fig. 2(c). Germination parameters for the wheat seedlings were calculated using the following equations. ${ }^{15,16}$

Germination potential is the percentage of the number of seeds actually germinated on the first day of germination, divided by the total number of sowed seeds.

$$
\text { Germination potential }=\frac{\text { number of seeds germinated at } 1 \mathrm{~d}}{\text { total number of seeds }} \times 100 \text {. }
$$

Volume 10, Issue 1, 2020 

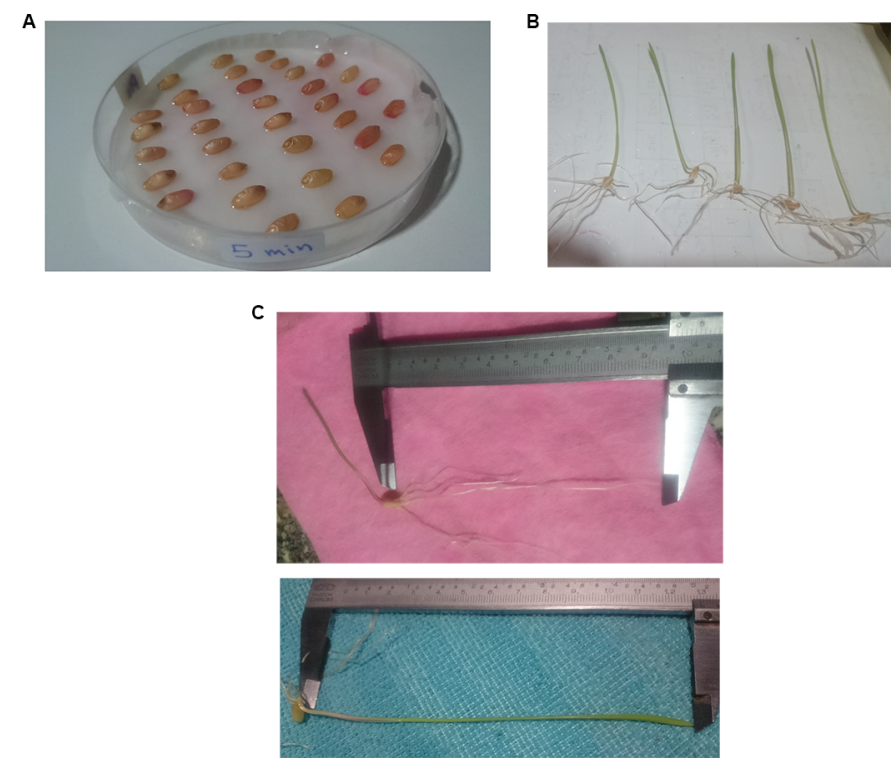

FIG. 2: Wheat seed germination: (a) seeds settled on filter paper in a Petri dish; (b) five germinated seedlings; (c) measurements by Vernier caliper of root (upper) and shoot (lower)

Germination rate is the percentage of the amount of seeds that were likely to germinate during a given period. This value was calculated from the percentage of seeds that actually germinated by the end of $4 \mathrm{~d}$, divided by total seeds sowed during this period.

$$
\text { Germination rate }=\frac{\text { number of seeds germinated after } 4 \mathrm{~d}}{\text { total number of seeds }} \times 100
$$

Germination index describes the number of seedlings that emerged daily, counted from the day of planting until germination completed at $4 \mathrm{~d}$, and given by the summation during $4 \mathrm{~d}$ as

$$
\text { Germination index }=\sum\left(G_{n} / D_{n}\right)
$$

where $G_{n}$ is the number of seedlings emerging on day $n$, and is day $D_{n}$ after planting.

Vigor index was calculated by multiplying germination index by total root lengths of the five seedlings considered, expressed in centimeters using the following equation:

Vigor index $=$ germination index $\times$ root length. 


\section{RESULTS AND DISCUSSION}

\section{A. Germination Results}

All measurements were replicated three times. We used the Statistical Package for the Social Sciences statistical analysis program to calculate germination parameters in the form of mean value \pm standard deviation. In Table 1, germination potential was calculated on day 1 of germination using Eq. (1), and germination rate and germination index were calculated at the end of the day 4 using Eqs. (2) and (3). Total shoot and root lengths were measured on day 10 of germination and summed for five seedlings that were arbitrarily chosen for each replicated measurement. Vigor index was calculated using Eq. (4) using corresponding data of shoot and root lengths. Lowercase letters $\mathrm{a}-\mathrm{c}$ in the Table 1 columns denote statistical differences, with different letters indicating significant differences among various treatments at the $p \leq 0.05$ level, according to Duncan's test.

After 5 min of plasma treatment, resulting values of germination parameters shown in Table 1 reveal an increase compared to those of controls. Germination potential on the first germination day increased by $15.18 \%$ in APJ, $18.19 \%$ in PAMI, and $20.23 \%$ in PAW. After $4 \mathrm{~d}$, germination rate increased by $3.05 \%$ in APJ, $5.08 \%$ in PAMI, and $6 \%$ in PAW.

By the end of $10 \mathrm{~d}$, total shoot length increased by $19.95 \%$ in APJ, $21.17 \%$ in PAMI, and 22.18 in PAW. For the same period, total root length increased by $32.78 \%$ in APJ, 33.04 in PAMI, and $35.10 \%$ in PAW. Results for plasma treatment of wheat seeds are given in Fig. 3. We can observe effects of the three plasma discharge schemes, namely, direct APJ, indirect PAW, and indirect PAMI, on values of germination potential (Fig. $3[\mathrm{a}]$ ), germination rate (Fig. 3[b]), total shoot length (Fig. 3[c]), and total root length (Fig. $3[\mathrm{~d}]$ ).

\section{B. Effects of Plasma on Seed Temperature, Ozone Production, and Radical Generation}

Temperature of seed outer surfaces were measured by an infrared thermometer and monitored using an infrared sensor. We measured ozone concentrations in air outside of the plasma jet using an ozone monitor (Bmt 932, Bmt Messtechnik, GmbH; Stahnsdorf, Germany) in APJ and PAMI for different RH values of water mist. Spectroscopic measurements were performed using a fiber optics spectrometer (AvaSpec-ULS2048 StarLine, Avantes, Apeldoorn, The Netherlands) with a wavelength range of 200-1100 $\mathrm{nm}$ and resolution of $0.9 \mathrm{~nm}$.

As shown in Fig. 4(a), during plasma exposure by dry-APJ, a slight increase in temperature occurred; however, this was in an acceptable range and thus not suspected of producing heat that could cause changes in seed morphology. Measurements of ozone concentrations are shown in Fig. 4(b) for APJ and PAMI at two different RH values in water mist. Ozone concentrations increased during the beginning of plasma treatment 


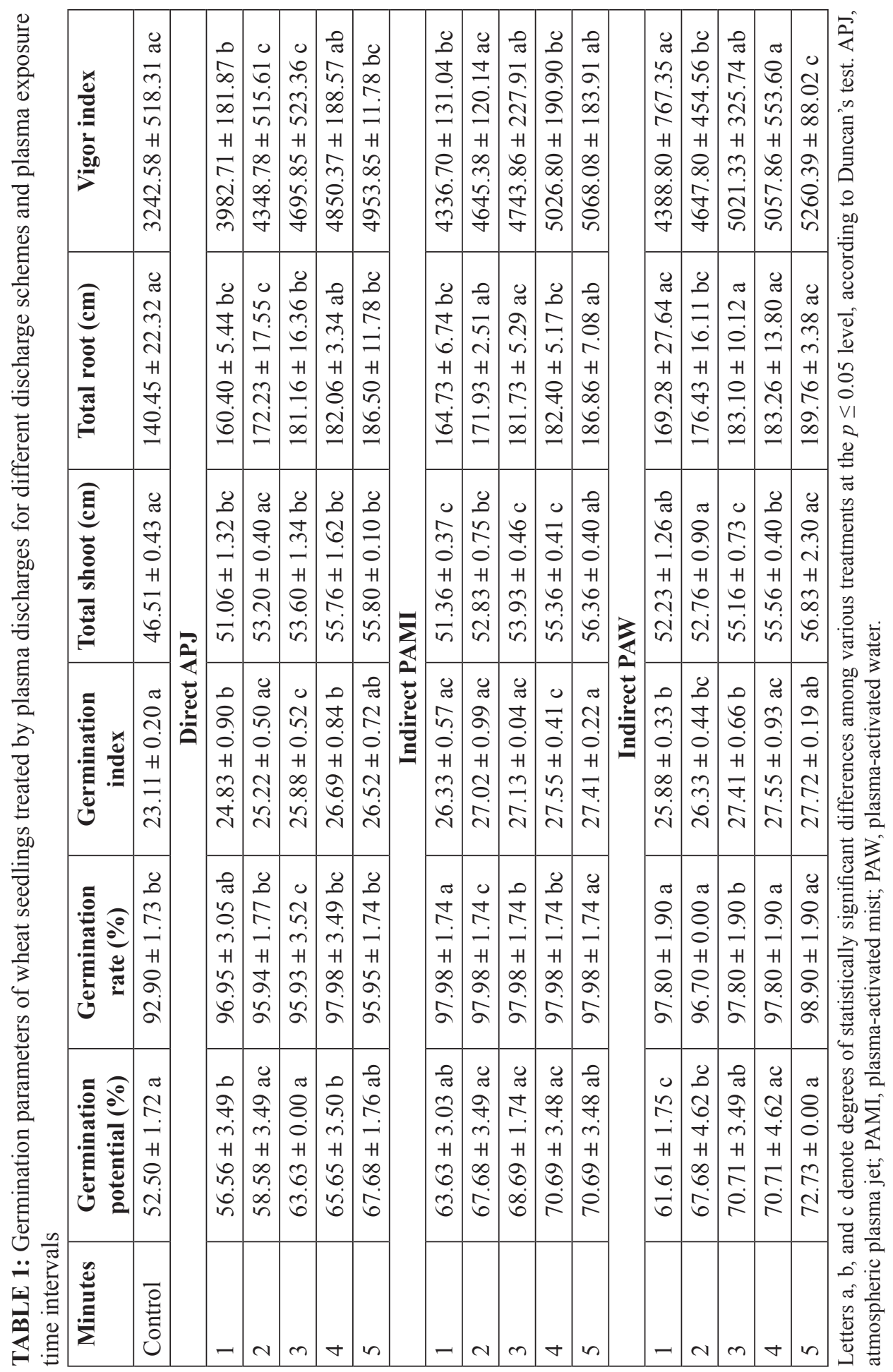


A

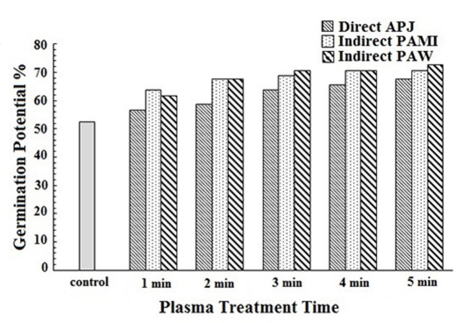

C

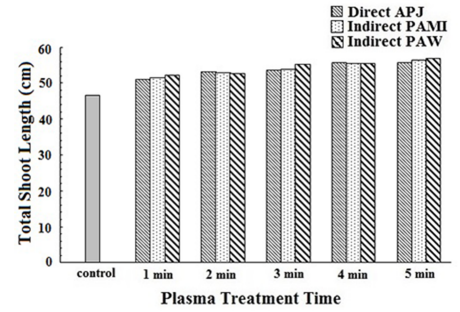

B

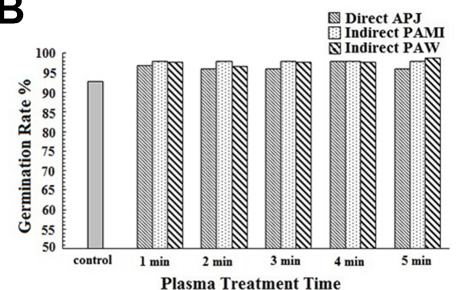

D

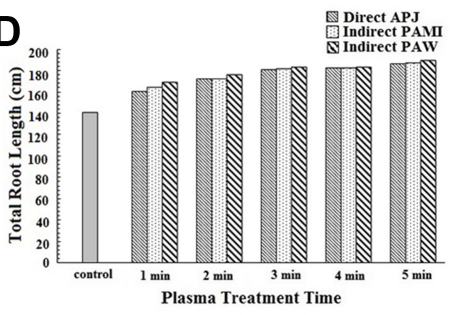

FIG. 3: Germination parameters for different plasma treatment-time intervals: (a) germination potential; (b) germination rate; (c) total shoot length; (d) total root length. APJ, atmospheric plasma jet; PAMI, plasma-activated mist; PAW, plasma-activated water
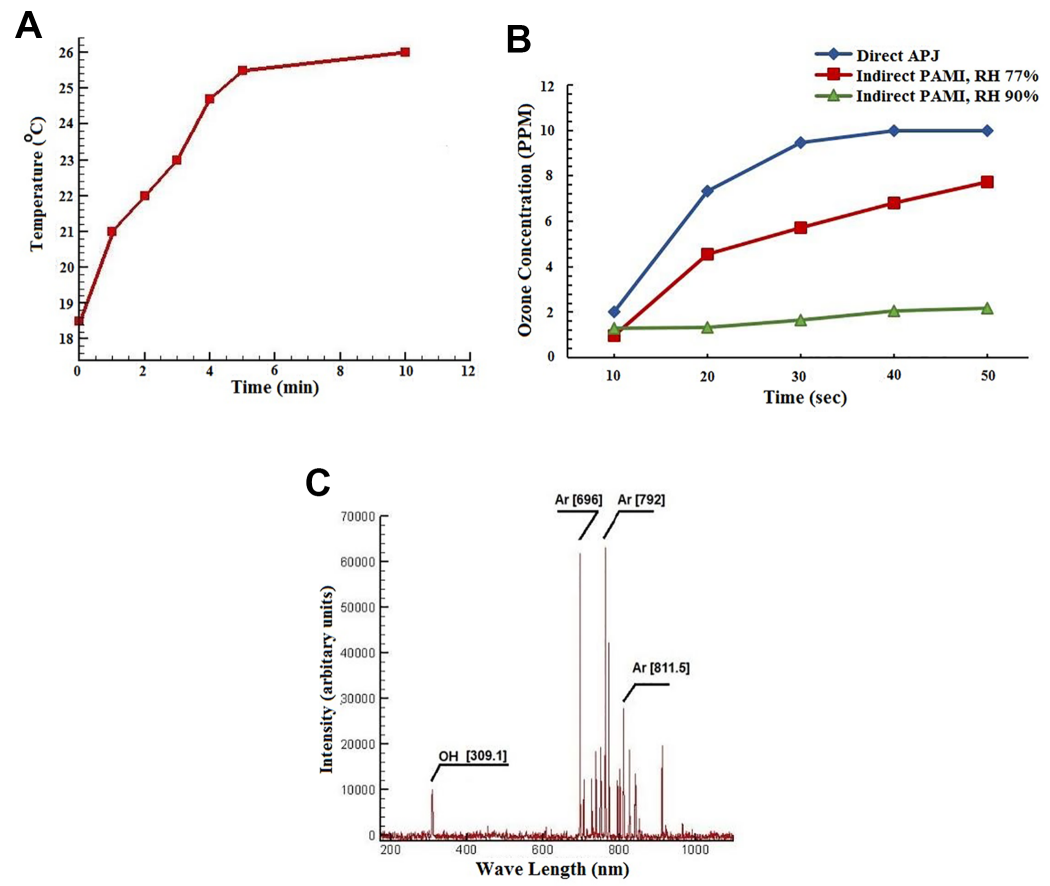

FIG. 4: (a) Seed temperature; (b) ozone production for different discharge mist RHs; (c) spectral line measurements. APJ, atmospheric plasma jet; PAMI, plasma-activated mist; PAW, plasmaactivated water; PPM, parts per million; $\mathrm{RH}$, relative humidity. 
and stabilized at greater plasma discharge times. In general, ozone concentrations were highest for APJ compared to PAMI, with different mist RHs. Usually, optical emission spectroscopy in the ultraviolet-visible range is used to identify atomic and molecular species that may be produced during plasma discharges. ${ }^{17}$ Here, we investigated emission spectra that were produced by argon plasma on APJ. Figure 4(c) gives the spectrum during seed treatment, showing argon lines and lines proper to $\mathrm{OH}$ hydroxyl radicals. Germination is also expected to be enhanced by effects of other reactive oxygen and nitrogen species (RONS), especially $\mathrm{H}_{2} \mathrm{O}_{2}, \mathrm{NO}^{2-}$, and $\mathrm{NO}^{3-}$ concentrations during wet treatment with water and mist. ${ }^{18,19}$ For a complete overview of RONS effects in the three plasma discharge configurations as related to wheat germination, more detailed measurements must be performed.

\section{Wettability of Treated Seeds}

The shape of a water drop on the surface of a seed coat can be considered to be an indication of the seed's surface wettability. We deposited a drop of distilled water onto seeds' surfaces before (control) and after plasma treatment by dry APJ for different treatmenttime intervals. The contact angle is defined as the angle between the solid surface and the tangent to the surface of the drop at the point of contact. In our experiment, contact angle was calculated using sessile drop analysis ${ }^{20}$ from images of water drops onto seed surfaces (shown in Fig. 5).

The decrease in water drop contact angles, observed in Fig. 6, is a clear indication of enhanced hydrophilization occurring on wheat seed surfaces as a result of plasma
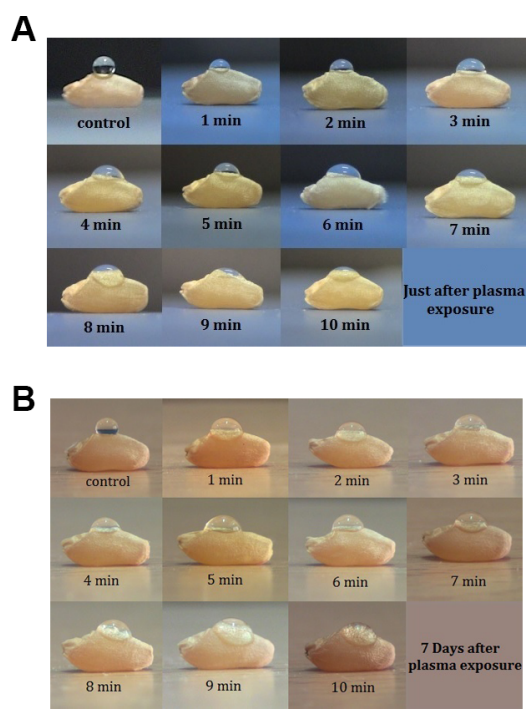

FIG. 5: Water drops on seed surfaces for different plasma treatment-time intervals: (a) just after plasma exposure; (b) $7 \mathrm{~d}$ after plasma exposure 


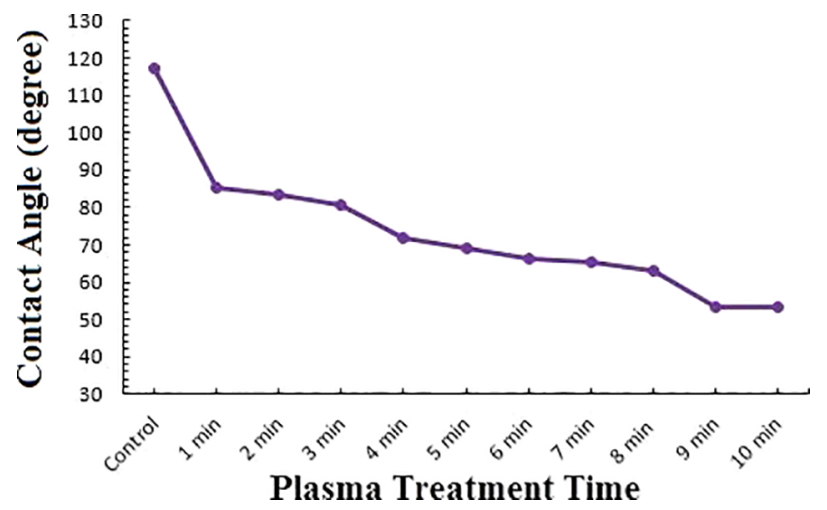

FIG. 6: Contact angle for different plasma treatment-time periods by APJ in dry exposure

treatment. ${ }^{21}$ By comparing photos of water drops on surfaces of seeds, in Fig. 5(a), taken just after plasma exposure, with those shown in Fig. 5(b) taken $7 \mathrm{~d}$ after treatment, we observed no significant changes regarding contact angles at corresponding times. This indicates that no clear hydrophobic recovery occurred after a few days of plasma treatment. This is in accordance with other observations that also did not report hydrophobic recovery a long time after plasma treatment. ${ }^{22}$

\section{Water Uptake of Treated Seeds}

The increase in wettability of seeds due to plasma exposure can be considered an enhancement of water uptake by seeds, which can be valuable for germination. This was verified for the APJ mode of operation by measuring water uptake per seed, following the technique described by Stolárik et al. ${ }^{23}$ We treated 100 wheat seeds using plasma for $1,2,3,4$, and $5 \mathrm{~min}$. Treatments at different times were replicated three times for statistical purposes. Each group of 100 seeds was weighed using an electronic balance (BEL Engineering, Monza, Italy) just after plasma exposure. This value was labeled dry weight (DW). After that, all seeds were hydrated with distilled water in Petri dishes, covered to prevent water evaporation, and then incubated for up to $2 \mathrm{~h}$ at room temperature. We then blotted seeds dry and weighed them for their fresh weight (FW). We repeated seed wetting every $2 \mathrm{~h}$ and $\mathrm{FW}$ was obtained at 2, 4, 6, and 8 hours for all seed groups. Water uptake was then calculated as follows:

$$
\text { Water uptake }(\mathrm{mg} / \mathrm{seed})=(\mathrm{FW}-\mathrm{DW}) / 100
$$

Figure 7 shows the increase in water uptake for treated seeds versus controls (untreated). After $2 \mathrm{~h}$ imbibition and 5 min plasma treatment, water uptake increased by $43.9 \%$. This result is evidence for increasing hydrophilization of seed surfaces treated by plasma and may explain the accelerated germination of treated seeds in comparison 


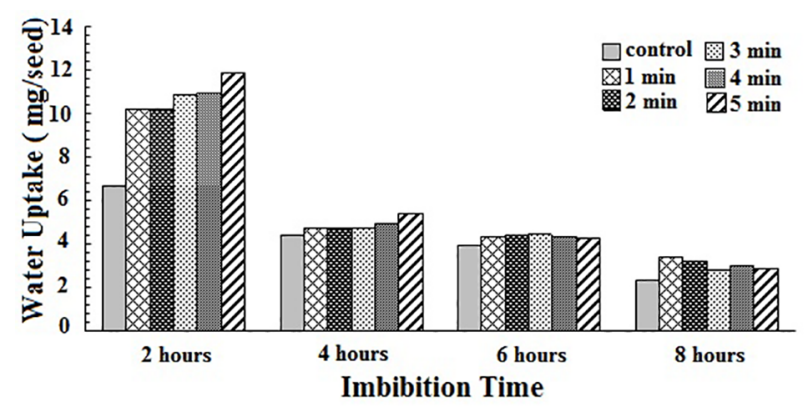

FIG. 7: Water uptake of wheat seeds at different imbibition time intervals

to untreated seeds. In the few hours following the imbibition process, water uptake decreased and surfaces of seeds seemed to reach water saturation.

In Fig. 8, the correlation between contact angles and water uptake shows increased water uptake with decreased contact angles. This can be considered a clear measure of increasing wheat surface hydrophilization along with plasma treatment.

\section{E. Effect of Plasma Treatment on Seed Surface Morphology}

In Fig. 9, images from a scanning electron microscope show surface morphology of plasma-treated wheat seeds compared to untreated seeds. In Figs. 9(b) and (c), obvious cracks on seed surfaces are seen for samples treated by plasma at different treatmenttime intervals compared to control seeds in Fig. 9(a). Cracks on seeds surfaces after

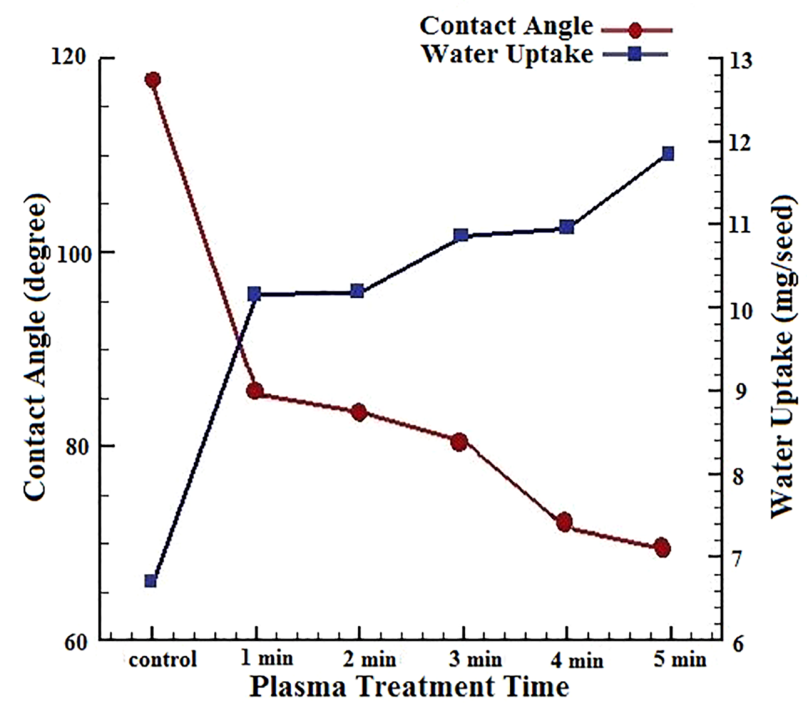

FIG. 8: Contact angle versus water uptake of wheat seeds at different plasma treatment times 

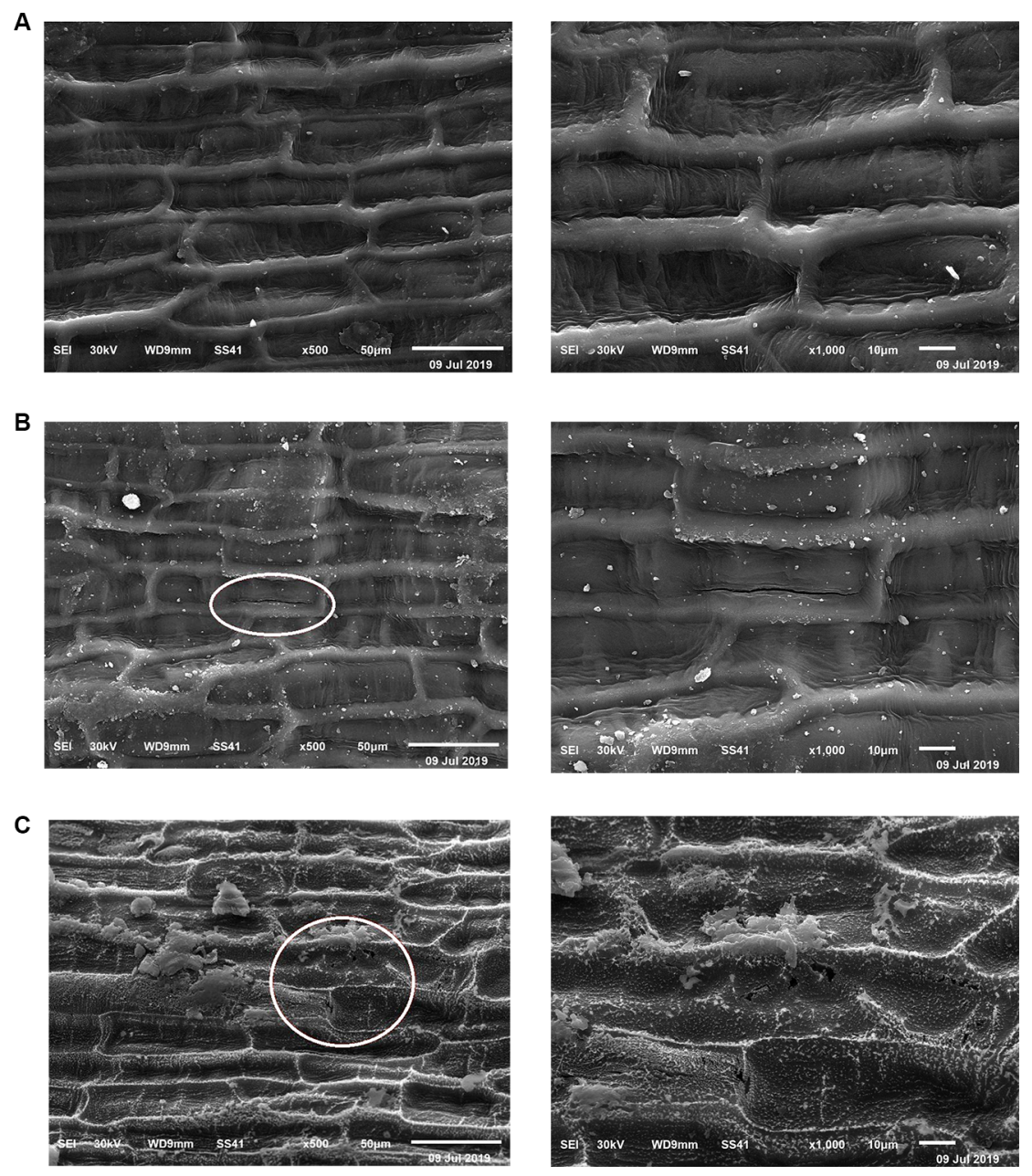

FIG. 9: Scanning electron microscope images of wheat seeds show: (a) untreated controls, (b) 3 min of plasma treatment, and (c) 10 min of plasma treatment for $500 \times$ (left-hand side) and 1000× (right-hand side) magnifications. For treated samples, contours in the $500 \times$ magnification photographs indicate magnified zones $(1000 \times)$ of treated samples.

plasma exposure have been observed in by other authors. ${ }^{24,25}$ These cracks were suggested as the possible reason for improved hydrophilicity of seed surfaces by plasma, as observed in Fig. 5, and the related enhancement in water uptake (Fig. 7).

\section{CONCLUSIONS}

We measured germination potential, germination index, vigor index, and shoot and root lengths for wheat seedlings at $4 \mathrm{~d}$ after plasma exposure. Compared to direct plasma treatment, results show significant enhancement in seed germination by indirect plasma 
activation medium of either water or mist. PAW shows greater effects than PAMI treatment. However, PAMI can be more suitable for treating large numbers of seeds on an industrial scale. Plasma treatment causes hydrophilization of the seed surface, leading to accelerated water uptake. Thus, we have shown that CAP green technology can offer increased crop production by accelerating wheat germination while respecting the environment.

\section{REFERENCES}

1. Food and Agriculture Organization of the United Nations. The future of food and agriculture. Alternative pathways to 2050 (summary version). Rome: FAO; 2018. p. 16-60.

2. Perlatti B, Forim MR, Zuin VG. Green chemistry, sustainable agriculture and processing systems: A Brazilian overview. Chem Biol Technol Agric. 2014;1(5):1-9.

3. Puač N, Gherardi M, Shiratani M. Plasma agriculture: A rapidly emerging field. Plasma Proc Polym. 2018;15(2):1700174.

4. Bourke P, Ziuzina D, Boehm D, Cullen PJ, Keener K. The potential of cold plasma for safe and sustainable food production. Trends Biotechnol. 2018;36(6):615-26.

5. Zahoranová A, Henselová M, Hudecová D, Kaliňáková B, Kováčik D, Medvecká V, Černák M. Effect of cold atmospheric pressure plasma on the wheat seedlings vigor and on the inactivation of microorganisms on the seeds surface. Plasma Chem Plasma Proc. 2016;36(2):397-414.

6. Perinban S, Orsat V, Raghavan V. Nonthermal plasma-liquid interactions in food processing: A review. Compr Rev Food Sci Food Safety. 2019;18(4):1985-2008.

7. Shewry PR, Hey SJ. The contribution of wheat to human diet and health. Food Energy Secur. 2015;4(3):178-202.

8. Dobrin D, Magureanu M, Mandache NB, Ionita M-D. The effect of non-thermal plasma treatment on wheat germination and early growth. Innov Food Sci Emerg Technol. 2015;29:255-60.

9. Guo Q, Wang Y, Zhang H, Qu G, Wang T, Sun Q, Liang D. Alleviation of adverse effects of drought stress on wheat seed germination using atmospheric dielectric barrier discharge plasma treatment. Sci Rep. 2017;7(1):16680.

10. Bahrami N, Bayliss D, Chope G, Penson S, Perehinec T, Fisk ID. Cold plasma: A new technology to modify wheat flour functionality. Food Chem. 2016;202:247-53.

11. Randeniya LK, de Groot GJJB. Non-thermal plasma treatment of agricultural seeds for stimulation of germination, removal of surface contamination and other benefits: A review. Plasma Proc Polym. 2015;12(7):608-23.

12. Sivachandiran L, Khacef A. Enhanced seed germination and plant growth by atmospheric pressure cold air plasma: Combined effect of seed and water treatment. RSC Adv. 2017;7(4):1822-32.

13. Massines F, Gherardi N, Naude N, Segur P. Glow and townsend dielectric barrier discharge in various atmosphere. Plasma Phys Control Fusion. 2005;47(12B):B577.

14. El Shaer M, Zaki A, Reda AM, Adel M, Mobasher M, Ali S. Effect of plasma activated mist on breast cancer cells. IEEE Trans Radiat Plasma Med Sci. 2018;2(2):103-8.

15. Tong JY, He R, Zhang XL, Zhan RT, Chen WW, Yang SZ. Effects of atmospheric pressure air plasma pretreatment on the seed germination and early growth of Andrographis paniculata. Plasma Sci Technol. 2014;16(3):260-6.

16. Guo Q, Meng Y, Qu G, Wang T, Yang F, Liang D, Hu S. Improvement of wheat seed vitality by dielectric barrier discharge plasma treatment. Bioelectromagnetics. 2018;39(2):120-31.

17. Han D. A spectroscopic study of the effect of humidity on the atmospheric pressure helium plasma jets. Curr Appl Phys. 2018;18(11):1375-80.

18. Judée F, Simon S, Bailly C, Dufour T. Plasma-activation of tap water using DBD for agronomy applications: Identification and quantification of long lifetime chemical species and production/consumption mechanisms. Water Res. 2018;133:47-59. 
19. Kučerová K, Henselová M, Slováková L, Hensel K. Effects of plasma activated water on wheat: Germination, growth parameters, photosynthetic pigments, soluble protein content, and antioxidant enzymes activity. Plasma Proc Polym. 2019;16(3):1800131.

20. Yuan Y, Lee TR. Contact angle and wetting properties. In: Braco G, Host B, editors. Surface Science Techniques Springer Series, Surface Sciences, Volume 51. Berlin, Germany: Springer-Verlag; 2013. p. 3-34.

21. Bormashenko E, Shapira Y, Grynyov R, Whyman G, Bormashenko Y, Drori E. Interaction of cold radiofrequency plasma with seeds of beans (Phaseolus vulgaris). J Exp Bot. 2015;66(13):4013-21.

22. Shapira Y, Chaniel G, Bormashenko E. Surface charging by the cold plasma discharge of lentil and pepper seeds in comparison with polymers. Colloids Surf B Biointerfaces. 2018;172:541-4.

23. Stolárik T, Henselová M, Martinka M, Novák O, Zahoranová A, Černák M. Effect of low-temperature plasma on the structure of seeds, growth and metabolism of endogenous phytohormones in pea (Pisum sativum L.). Plasma Chem Plasma Proc. 2015;35(4):659-76.

24. Dhayal M, Lee SY, Park SU. Using low-pressure plasma for Chartamus tinctorium L. seed surface modification. Vacuum. 2006;80(5):499-506.

25. Sera B, Spatenka P, Sery M, Vrchotova N, Hruskova I. Influence of plasma treatment on wheat and oat germination and early growth. IEEE Trans Plasma Sci. 2010;38(10):2963-8.

Volume 10, Issue 1, 2020 
